УДК 340.5:341.1/8

\title{
$X$. Бехруз
}

\section{СРАВНИТЕЛЬНОЕ МЕЖДУНАРОДНОЕ ПРАВО - АКТУАЛЬНОЕ НАПРАВЛЕНИЕ ПРАВОВЫХ ИССЛЕДОВАНИЙ}

В современных условиях в связи с усложнением объектов научных исследований становится очевидной необходимость взаимодействия между различными отраслями научных знаний. Это объясняется прежде всего тем, что новые, более сложные объекты исследований оказываются в предметном поле различных отраслей науки, для объективного изучения которых необходимо задействовать весь арсенал методологии этих наук. Данное обстоятельство обуславливает междисциплинарный характер научных исследований, в результате чего научно-исследовательский процесс достигает необходимых целей. Это в полной мере относится к юридической науке в целом и к таким ее важнейшим отраслям, как международное право и сравнительное правоведение.

Сравнительное международное право как сфера научных знаний воспринимается исследователями неоднозначно. Оно представляет собой нечто иное, чем просто взаимодействие международного права и сравнительного правоведения.

Использование международным правом сравнительно-правового метода, разработанного в рамках методологии теории права и получившего развитие в рамках методологии сравнительного правоведения, является очевидной необходимостью для исследования его объекта и предмета. Безусловно, его применение наряду с другими методами обеспечивает результативность и эффективность международно-правовых исследований. По мнению многих правоведов-международников, именно это формирует содержание понятия «сравнительное международное право». Однако, на наш взгляд, использование данного метода не исчерпывает потенциал взаимодействия международного права и сравнительного правоведения. Итак, в понятие «сравнительное международное право» исследователями вкладывается разная содержательная нагрузка. Цель статьи заключается в изложении авторского видения данной проблематики. Для этого рассмотрим и проанализируем определенные утверждения. 
Сравнительное правоведение - современное направление научноправовых исследований. Накопленный потенциал сравнительного правоведения, проявляющийся в широких возможностях использования теории, методологии, а также результатов сравнительно-правовых исследований в юридической теории и практике, является неисчерпаемым. Реализация этого потенциала при изучении основных правовых систем позволяет выйти на новый уровень накопления и систематизации результатов исследований.

Важнейшим направлением содержания исследований сравнительного правоведения являются знания, имеющие функциональную природу, выходящие за рамки национальных правовых систем и имеющие универсальную теоретическую и практическую ценность. Функциональное назначение сравнительного правоведения проявляется в трех направлениях: практическом (или профессиональном), социологическом и культурном. Практическая значимость сравнительного правоведения наиболее ярко проявляется в условиях интернационализации экономики, создания глобального информационного общества, что обуславливает формирование региональных и отчасти универсальных правовых пространств.

С позиций цивилизационного подхода важным направлением исследований сравнительного правоведения выступает изучение множественности правовых реальностей, отражающих многообразие правовых явлений. Целеустремленная разработка вопросов сравнительного правоведения выводит юридическую науку на новый уровень постижения права как явления цивилизации и культуры $[1$, с. 8].

Многообразие существующих правовых систем и правовых культур основывается на разных правовых ценностях существовавших ранее и существующих в настоящее время культур и цивилизаций. Согласно ЮНЕСКО сравнительное правоведение наряду с международным правом выполняет общегуманитарную функцию, связанную с налаживанием «мостов» между различными культурами и цивилизациями путем их изучения и понимания [2, c. 93].

Важным условием для развития современного общества является необходимость снижения напряженности и конфликтности цивилизации и культур. Этому способствует исследование закономерностей формирования и динамики их трансформации. Признание разнообразных проявлений общественной жизни, восприятие различного образа жизни и соответствующих основ их правового регулирования, различных философских и идеологических основ и моделей социального развития выступает методологической основой таких исследований. Сравнительное правоведение может стать платформой для интеллектуального обмена, обеспечивающего поступательное развитие общества. Сравнительное правоведение также способствует выявлению возможностей взаимодействия и взаимопонимания различных правовых культур.

Сравнительное правоведение, анализируя формирование и функционирование различных правовых систем, а также диалектический характер 
их взаимодействия, имеет непосредственный выход на общетеоретические представления о праве как таковом. Сравнительно-правовые исследования, используя накопленные общетеоретические представления о праве, выходят на уровень анализа отраслевых юридических наук, что придает им междисциплинарный характер.

В таком ракурсе сравнительное правоведение не может отожествляться со сравнительно-правовым методом, который формируется в рамках теории права. Безусловно, сравнительно-правовой метод остается краеугольным камнем методологии сравнительного правоведения, однако он не исчерпывает его содержание и потенциал. Точно так же фрагментарное либо систематическое применение сравнительно-правового метода не может отождествляться с взаимодействием международного права со сравнительным правоведением. Сравнительное правоведение стало признанным научным направлением, имеющим свой предмет и методологию.

Международное право - основа современного международного правопорядка: современное состояние и современные вызовы.

Современный международный правопорядок представляет собой систему международно-правовых отношений, придающую им структурную устойчивость на основе целей и принципов международного права.

Современное международное право представляет собой результат длительного исторического развития, является достоянием цивилизации и одной из важнейших общечеловеческих ценностей, без которой не возможно формирование межгосударственных отношений. Конфигурация и диалектика международных взаимоотношений формируется на основе добросовестного выполнения обязательств их субъектов.

В послевоенный период развития международное право преимущественно было связано с задачами по укреплению мира и безопасности. Современное международное право сталкивается с новыми вызовами и новыми задачами. Главная проблема на этом пути - разрушение прежнего правопорядка в результате несоблюдения, казалось бы, незыблемых принципов и основных норм международного права как основы современного международного правопорядка.

После распада Советского Союза и социалистического лагеря и особенно после террористических актов 11 сентября 2001 г. современный международный правопорядок переживает кризис. Его ключевым фактором становится военно-политический фактор.

Для выхода из сложившейся ситуации выдвигаются предложения о пересмотре основных принципов, на которых на протяжении полувека базировался международный правопорядок. В организационном плане предлагается реорганизовать ООН, особенно Совет Безопасности ООН, выступающий в качестве базы принятия решений по архитектуре современного международного правопорядка.

Причины кризиса исследователи называют разные. В современной науке международного права наиболее ярко выражены «реалистический» и «неолиберальный» подходы к международному праву. Сторонники первой 
концепции оценивают международное право довольно скептически. Для них система международных отношений представляется в качестве анархии, в рамках которой каждое государство руководствуется не столько соображениями международно-правового порядка или общечеловеческими интересами, сколько собственными национальными интересами, полагаясь при этом не на механизмы международного права, а на инструменты самопомощи. Вместе с тем «реалисты» признают, что международное право формирует определенный порядок в международных отношениях. Что касается «неолиберального» подхода, то его сторонники исходят из того, что в международных отношениях существует определенный порядок, одним из важнейших проявлений которого является система международного права. Международное право, по их мнению, хоть и не является таким же эффективным, как внутреннее право, все-таки представляет собой полноценное право, оказывающее заметное влияние на социальные отношения [3].

Анализируя существующие взгляды на современное состояние международного права, необходимо констатировать присутствие обоснованных доводов как в «реалистическом», так и в «неолиберальном» подходах к международному праву. Вместе с тем международное право по-прежнему выступает в качестве важнейшего инструмента, систематизирующего и регулирующего международные отношения. Однако оно не может в корне менять отношения, складывающиеся между государствами и другими субъектами международного права.

Направления взаимодействия сравнительного правоведения и международного права.

В условиях глобализации происходит изменение всех основ общественно-политической жизни современного общества, в котором аккумулируются общечеловеческие проблемы. Глобализационные процессы приводят к изменениям в государственно-правовом устройстве как на национальном, так и на международном уровнях, в том числе связанным с формированием институциональных и нормативных механизмов, носящих наднациональный характер.

Взаимодействие сравнительного правоведения и международного права в контексте современных международных отношений сводится к нескольким важнейшим и наиболее значимым направлениям.

1. Право в настоящее время переживает фазу активного развития, поскольку новый век сопровождается активными трансформационными процессами во всех сферах. Происходят качественные изменения сущностных и содержательных характеристик многих правовых явлений, в том числе правовых систем.

Правовое бытие в современных условиях становится многоуровневым: национальное право, региональное право и международное право дополняются универсальным (транснациональным) правом. Функционирование данных институциональных и нормативных механизмов, носящих национальный и наднациональный характер, не может происходить без соот- 
ветствующей правовой регламентации. Универсальное (мировое) право, о котором мечтали организаторы I Международного Конгресса сравнительного права в 1900 г., в современных условиях фигурирует как конгломерат данных правовых массивов.

Это ставит перед юридической наукой новые задачи, связанные с поиском ответов на вопрос о дальнейшей судьбе многих правовых явлений. В частности, необходимо выяснить, как создать условия для правовых решений, связанных с нынешним уровнем интеграционных тенденций с учетом особенностей традиционной догмы права; как использовать сложившиеся демократические институты государственной власти в условиях кризиса суверенитета государства и формирования наднациональных механизмов и многое другое.

Необходимо согласиться с утверждением В.В. Оксамытного, указывающего на ограниченность рассмотрения правовой системы лишь в рамках государственных пределов, поскольку правовая система как политико-юридический феномен отражает многообразие современного мира, базирующегося на динамично развивающихся принципах и нормах, отвечающих в своем проявлении процессам глобализации [4, с. 67].

Как отмечает Г.Дж. Берман, развивающаяся система мирового права включает в себя не только международное публичное право, то есть право, созданное национальными государствами в процессе взаимоотношений (в том числе право, регулирующее деятельность ООН и ее вспомогательных межгосударственных организаций), но и громадную систему норм договорного и обычного права, которые регулируют отношения между физическими и юридическими лицами, вовлеченными в добровольную деятельность вне национальных границ. Мировое право является новым названием того, что мы когда-то называли правом народов, общим правом человечества, охватывающим общие черты различных правовых систем, правовых систем разных народов мира [5, с. 13].

2. Диалектика и динамика взаимопроникновения различных әлементов данных правовых массивов - современное направление исследований, как сравнительного правоведения, так и международного права. В этих условиях сравнительное правоведение выступает современной сферой научных знаний, решающей задачи существования и развития права и государства в национальном, региональном, международном и наднациональном измерениях, когда динамика и темпы развития социальной жизни, многообразие культур и индивидуальная их самобытность обуславливают формирование новых требований к функциональному назначению правовой системы.

Считаем, что при разработке новых концепций, определяющих современное состояние теории права и пути трансформации права и правовых систем в современных условиях, важное методологическое значение имеют идеи, высказанные П.М. Рабиновичем, о необходимости ответить на вопрос о том, что (какое явление) отображается терминопонятием «право». Ответ на этот вопрос является научной миссией именно всеобщей 
(универсальной) теории права. В этом коренится принципиальный ответ на вопрос о месте сравнительного правоведения, по крайней мере его общетеоретической части, в системе всей теоретической юриспруденции, то есть о соотношении сравнительного правоведения с другими сферами, прежде всего с универсальной теорией права. Она призвана стать «общей частью» всех теорий, непосредственным объектом которых выступают, соответственно, либо внутригосударственное (национальное) позитивное право любых стран, либо международное право, либо общее и особенное право любых правовых систем и иных правовых явлений. С некоторой долей условности можно утверждать, что целостная наука теории права состоит из двух основных подразделений: ее общей части (универсальной теории) и ее специальной части (теории права национального, теории права международного, теории сравнения правовых систем и других правовых явлений) [6, с. 118].

Таким образом, сравнительное правоведение способствует формированию новой правовой теории путем создания категорий и понятий общего применения. Оно также дает ответ на вопрос о целесообразности или нецелесообразности правовой трансплантации в рамках правовой аккультурации.

3. Задача современной юридической науки заключается в формировании нового правового мышления, которое станет основой для современной правовой практики, требующей от правоприменителей навыков юридической деятельности, учитывающей интегративный характер правовых массивов, а также умение работать в рамках различных правовых систем.

Размышляя над возможностями сравнительного правоведения в направлении оптимизации юридического образования, К. Осакве отмечает, что сравнительное правоведение разрушает правовую ксенофобию, облегчает понимание зарубежных правовых систем, способствует изучению и использованию собственного национального права, повышает культурный уровень обучающихся, в итоге подкрепляя фундаментальность юридического образования [7, с. 59].

Современное профессиональное правовое мышление предполагает выход за рамки национального права и учет правовых принципов и правовых положений наднациональных правовых массивов. Правоприменитель в современных условиях обязан демонстрировать знания и умение работать не только с национальной правовой базой, но и с принципами и нормами, содержащимися в международных универсальных и региональных правовых актах. Считаем, что именно сравнительное правоведение во взаимодействии с международным правом и теорией права способно обеспечить формирование такого уровня профессионального мышления.

Накопившиеся проблемы в международных отношениях требуют нового адекватного мышления в архитектуре современного международного правопорядка, основанного на диалоге цивилизаций, предполагающем уважительное отношение к различным ценностям и культурам. 
4. Концептуальное осмысление понятия регионального права также является актуальным. Региональное право как особая разновидность международного права все сильнее включается в сферу правового регулирования отношений между государствами отдельного региона с учетом их особенностей. Современные тенденции правового развития свидетельствуют о растущем влиянии регионального права на систему права национального и региональных правовых систем на правовой панораме мира. Сравнительно-правовые исследования в данной сфере способствуют адекватному осмыслению этих сложных теоретико-правовых проблем и укреплению региональных правовых пространств, базирующихся на региональном праве. Именно региональное право является мягкой и эффективной формой унификации и гармонизации законодательства с учетом особенностей различных регионов.

Не вызывает сомнений, что источником устойчивого развития современного общества является многообразие культур и диалог между ними. В Хартии Земли, провозглашенной ООН, говорится: «Наше культурное разнообразие является ценным наследием, и различные культуры найдут собственные пути к реализации своего видения устойчивого образа жизни».

Проблематика диалога культур и партнерства цивилизаций неоднократно обсуждалась на различных международных научных мероприятиях, участники которых отмечали необходимость формирования принципов, лежащих в основе такого диалога, как необходимой основы для сосуществования различных цивилизаций и культур. Диалог культур, по мнению А.А. Гусейнова, предполагает особого рода единство между ними. Диалог предполагает такую соотнесенность и связанность культур между собой, когда они объединены общностью конечных жизненных целей, взаимно дополняют друг друга, нуждаются друг в друге, не могут существовать друг без друга. Диалог культур предполагает общность основоположений, которые только и могут сформировать адекватное пространство такого диалога. С другой стороны, диалог культур возникает из их отличий. Качественные различия культур - это не только предпосылка и основа диалога, но и его результат в том смысле, что диалог не снимает эти различия, а в определенном смысле обостряет их. Эффективность диалога культур заключается в сочетании общезначимого (универсального) с самобытным. Продуктивным может быть движение, отталкивающееся от самобытности культур и тем самым возникающее из внутренних источников каждого из них отдельно. Без взаимоуважительных отношений, основанных на признании изначального равенства культур по ценностным критериям и, следовательно, суверенности каждой из них в формулировке собственных ценностных критериев и приоритетов, никакого диалога между ними быть не может [8, с. 65].

Сегодня проблемой является не только сохранение уникальности, самобытности правовых культур, сформированных различными цивилизациями и этносами, но и обеспечение суверенитета национальных государств, недопущения вмешательства в их внутренние дела. Современные между- 
народные отношения не могут существовать и развиваться без сотрудничества субъектов международных отношений в условиях замкнутости правовых культур. Происходят процессы правовой аккультурации, то есть взаимодействия между правовыми системами и правовыми культурами на уровне законодательства, судебной практики, юридической науки, юридического образования и так далее.

Эти процессы имеют принципиальное значение для формирования архитектуры современного международного правопорядка. Ведь современный международный правопорядок может быть устойчивым лишь при условии признания и закрепления равноправия всех субъектов международных отношений.

Необходимость диалога правовых систем и правовых культур обуславливается неизбежностью сосуществования современных цивилизаций, с каждым днем она становится все очевиднее. Современный мир характеризуется нарастающей тенденцией к интеграционным процессам путем взаимодействия правовых систем. Замкнутость правовых систем приводит к их застою, такие системы не могут соответствовать потребностям и интересам современного общества, вследствие чего вопрос их дальнейшего развития становится проблематичным. Выход за рамки национального видения права, примат общечеловеческих ценностей в развитии цивилизации и ее правовой составляющей относятся к главным направлениям развития современного общества.

Диалог правовых культур должен осуществляться исходя из того, что полная и неискаженная картина правового регулирования в обществе может быть составлена на основе познавательного материала, добытого в результате научного, нормативного и ценностного постижения правовой действительности. Одной формы познания, даже если она является научной, недостаточно. Одну из форм нельзя искусственно преувеличивать за счет других. Только вместе они могут претендовать на более-менее правильное объяснение реальности [9, с. 76-77]. Глобальный диалог требует адекватного отношения между представителями различных цивилизаций и культур, основанного на взаимном уважении и гармоничном соединении разнообразия и единства.

Резюмируя сказанное, следует отметить, что сравнительное международное право можно рассматривать как новое качество, новый уровень взаимодействия таких важнейших юридических наук, как международное право и сравнительное правоведение. Кризис в международных отношениях, который непосредственно отражается на международном праве, ставит перед ним сложную задачу по его преодолению. Наука международного права как одна из зрелых юридических наук стремится к разрешению этих непростых задач. Считаем, что эффективность и быстрота их решения напрямую зависят от взаимодействия науки международного права с другими юридическими науками, в частности со сравнительным правоведением. Сегодня сравнительному правоведению принадлежит роль связующего звена между классическим национальным и международным правом, что 
в значительной мере способствует пересмотру устоявшихся стереотипов, формированию нового взгляда на казавшиеся незыблемыми нормы и постулаты. Сравнительное правоведение может помочь науке современного международного права найти баланс между динамикой и статикой общественного развития, что необходимо для формирования принципов и норм, требующих общего признания и общей для всех субъектов международного права значимости.

\section{Литература}

1. Алексеев С.С. Предисловие / С.С. Алексеев // Рабель Э. Задачи и необходимость сравнительного правоведения / Э. Рабель ; пер. с нем. под ред. Б.М. Гонгало. - Екатеринбург : Российская школа частного права (Уральское отделение), 2000. - С. 4-9.

2. Кресин А.В. Вопрос о ценностном потенциале сравнительного правоведения в деятельности ЮНЕСКО и международного комитета сравнительного права / А.В. Кресин / / Евразийский юридический журнал. - 2011. - № 9. - С. 90-93.

3. Мережко А.А. Кризис современной миросистемы и будущее международного права в XXI веке / А.А. Мережко / / Альманах міжнародного права. - 2010. - Вип. 2. - С. 12-24. [Электронный ресурс]. - Режим доступа : http:// nbuv.gov.ua/j-pdf/amp_2010_2_4.pdf.

4. Оксамытный В.В. Правовые системы в XXI веке: новые подходы к классификации / В.В. Оксамытный // Європейське право та порівняльне правознавство : зб. ст. / за ред. Ю.С. Шемшученка та ін. - К. ; Шамборі : Логос, 2010. - С. 50-71.

5. Берман Г.Дж. Мировое право: экуменическая юриспруденция Святого Духа / Г. Дж. Берман / / Представительная власть - XXI век: законодательство, комментарии, проблемы. - 2005. - № 1. - С. 9-13.

6. Рабинович П.М. Всеобщая (универсальная) теория права как единый концептуальный базис теории национальной, международной и сравнительной юриспруденции / П.М. Рабинович / / Порівняльне правознавство: сучасний стан і перспективи розвитку : зб. наук. праць / за ред. С.В. Ківалова, Ю.С. Шемшученка. - О. : Фенікс, 2013. - С. 117-119.

7. Осакве К. Размышление о природе сравнительного правоведения: некоторые теоретические вопросы / К. Осакве / / Журнал зарубежного законодательства и сравнительного правоведения. - 2006. - № 3. - С. 54-71.

8. Гусейнов А.А. Диалог культур: возможности и пределы / А.А. Гусейнов / / Диалог культур и партнерство цивилизаций : матер. VIII Междунар. Лихачевских науч. чтений (г. Санкт-Петербург, 22-23 мая 2008 г.). - СПб. : Изд-во Санкт-Петербургского гуманит. ун-та профсоюзов, 2008. - С. 65-68.

9. Мальцев Г.В. Социальные основания права / Г.В. Мальцев. - М. : Норма, 2007. - 800 с.

\section{А н н о т а ци я}

Бехруз $X$. Сравнительное международное право - актуальное направление правовых исследований. - Статья.

В статье рассматривается сравнительное международное право как новое качество взаимодействия международного права и сравнительного правоведения. Международное право представлено как основа современного международного правопорядка. Рассмотрены наиболее важные направления взаимодействия международного права и сравнительного правоведения. Акцентируется внимание на потенциале этого взаимодействия, проявляющегося в расширении возможностей использования теории, методологии и результатов сравнительно-правовых исследований в юридической теории и практике.

Ключевые слова: сравнительное международное право, сравнительное правоведение, международное право, глобализационные процессы, современные международные отношения. 


\section{Анот а ці я}

Бехруз $X$. Порівняльне міжнародне право - актуальний напрям правових досліджень. - Стаття.

У статті досліджено порівняльне міжнародне право як нову якість взаємодії міжнародного права й порівняльного правознавства. Міжнародне право розглянуто як основа сучасного міжнародного правопорядку. Охарактеризовано найважливіші напрями взаємодії міжнародного права та порівняльного правознавства. Акцентується увага на потенціалі цієі взаємодії, що проявляється в розширенні можливостей використання теорії, методології та результатів порівняльно-правових досліджень у юридичній теорії й практиці.

Ключові слова: порівняльне міжнародне право, порівняльне правознавство, міжнародне право, глобалізаційні процеси, сучасні міжнародні відносини.

\section{S u m m a r y}

Bekhruz Kh. Comparative international law - the actual direction of legal studies. Article.

The article deals with the comparative international law as a new quality of interaction between international law and comparative law. International law is presented as the foundation of contemporary international law and order. The most significant areas of cooperation between the international and comparative law. The attention is focused on the potential of this interaction, as manifested in the expansion of the possibilities of using the theory, methodology, and results of comparative legal research in legal theory and practice.

Key words: comparative international law, comparative law, international law, globalization processes, modern international relation. 